\section{A good servant but a bad master: Finnish Translators' Perceptions on Translation Technology}

Leena Salmi

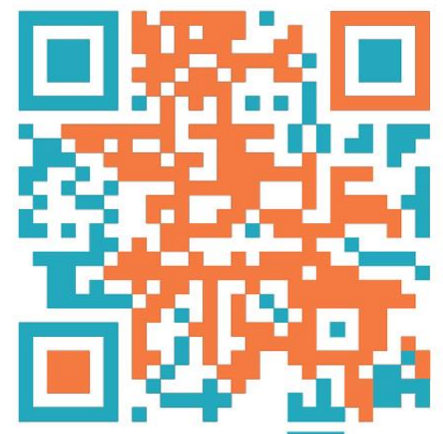

revista.trädumàtica

Abstract

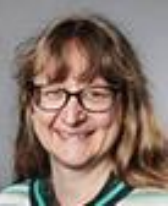

Leena Salmi

University of Turku leena.salmi@utu.fi; ORCID: 0000-0002-4725-3844
This paper reports the results of a survey measuring Finnish professional translators' $(\mathrm{N}=450)$ perceptions on translation technology. The paper also introduces a tool that can be used to study the perception of such changes, the NEMP model (New Educational Models or Paradigms). Main results indicate that translation technology is perceived by professional translators as an efficient tool that has changed translating in practice, but does not encourage to creativity. Business translators seem to have a more positive perception on translation technology than other respondents (literary or audiovisual translators). As for the method, the results indicate that the NEMP model is a useful method for studying the perception of translation technology.

Keywords: professional translators; translation technology; CAT tools; efficiency; attitudes

\section{Resum}

Aquest article mostra els resultats d'una enquesta que mesura les opinions dels traductors professionals finlandesos $(\mathrm{N}=450)$ quant a les tecnologies de la traducció. El treball també presenta una eina que pot utilitzar-se per estudiar la percepció d'aquests canvis, el model NMEP (Nous Models Educatius o Paradigmes). Els principals resultats indiquen que els traductors professionals perceben les tecnologies de la traducció com una eina eficient que, a la pràctica, ha canviat l'exercici de la traducció, però que no fomenta la creativitat. Els traductors empresarials semblen tenir-ne una percepció més positiva que altres enquestats (traductors literaris o audiovisuals). Pel que fa al mètode, els resultats indiquen que el model NMEP és un mètode útil per analitzar les opinions que generen les tecnologies de la traducció.

Paraules clau: traductors professionals; tecnologies de la traducció; eines CAT; eficiència; actituds 
Este artículo expone los resultados de un estudio que mide la percepción que tienen los traductores profesionales de finlandés $(\mathrm{N}=450)$ de las tecnologías de la traducción. Además, presenta una herramienta que permite estudiar cómo perciben los cambios que han provocado en su trabajo: el modelo NEMP, por sus siglas en inglés (Nuevos Modelos o Paradigmas Educativos). Los principales resultados muestran que los traductores profesionales consideran que las tecnologías de la traducción son una herramienta eficaz que ha modificado la práctica de la traducción, pero que no estimula la creatividad. Los traductores no literarios parecen tener una percepción más positiva que los traductores literarios y audiovisuales. En cuanto al método, los resultados indican que el modelo NEMP resulta útil para estudiar cómo son percibidas las tecnologías de la traducción.

Palabras clave: traductores profesionales; tecnologías de la traducción; herramientas TAO; eficiencia; actitudes

\section{Introduction}

The translation profession is undergoing multiple changes. The development of technology has brought a shift from typewriters to word processors, from time spent in a library to the use of search engines on the Web, from paper-based archives to translation memory systems, and this is transforming "a predominantly humanist profession to an increasingly technology-driven practice" (Koskinen \& Ruokonen, 2017: 8). As the development of technology has been very rapid, translators have often had to acquire new technical skills such as post-editing machine translations in continuous education or as part of informal, lifelong learning. The change has also brought new forms of work such as boundaryless working (flexibility of working hours, place and roles) and globalized production networks.

This article focuses on how translators perceive the changes translation technology has brought into their work. It reports results from a survey administered to professional translators in Finland and compares the results to responses provided by translation students in an earlier survey (L. Salmi, 2014). The methodology also introduces a new tool, the NEMP model (New Educational Models or Paradigms), which can be used to study the perception of such changes. This is the first time NEMP has been adapted to the context of translation.

\section{Background and related work}

As Olohan (2019: 389) points out, surveys on the use of translation technology "offer a snapshot of tool use among its targeted population, and potentially also some indicators of attitudes to technology." Recent industry surveys indicate that translation memories (TM) are widely used by professional translators: according to the European Language 
Industry Survey (ELIS) (2020: 51), nearly 60\% of respondents use TMs on a daily basis, while the CSA Survey (Pielmeier \& O'Mara, 2020: 41-42) reports that TMs were used on most projects by two-thirds (66\%) of respondents. The ELIS had 809 responses submitted by translation companies, individuals and training institutes in Europe, including Russia, Turkey and Ukraine. The CSA Survey had 7,363 responses from freelance and in-house translators and interpreters worldwide. Machine translation (MT) is not (yet) as widely used: according to the ELIS (2020: 51),60\% of respondents use it only occasionally and less than 20\% daily, and 45\% of the CSA Survey (Pielmeier \& O'Mara, 2020: 42) respondents say they never use it, while $22 \%$ report using it on most projects, even if it is not requested by the client.

The terms 'translation technology' and 'CAT tools' are sometimes used interchangeably. Bowker and Fisher (2010: 60) define computer-assisted translation (CAT) as "the use of computer software to assist a human translator in the translation process." As examples, they list TMs, terminology tools and Translation Environment Tools (TEnT), which may have various components such as concordancers, term extractors, project management and quality control modules, as well as MT systems. Similarly, the CSA survey (Pielmeier \& O'Mara, 2020: 42) lists, under the heading "Translation technologies used", tools such as TMs, quality checkers, terminology management, translation management systems and MT.

Do translators find that the use of translation technology increases their productivity and efficiency? Well, yes and no. In the CSA Survey (Pielmeier \& O'Mara, 2020: 41-42), the use of TMs was connected to delivering better quality by $76 \%$ of the respondents, and to delivering faster by $86 \%$ of the respondents. MT was considered less efficient: only $23 \%$ agreed that they deliver better quality when using MT, and $52 \%$ that they deliver faster (idem). Despite occasional usage and lower efficiency, MT and post-editing were identified as the strongest trend expectation in the ELIS (2020: 67) by all types of respondents (companies, independent professionals, trainers, developers and clients).

Alonso and Vieira (2021) review the history of the use of translation technology and its impact on the translation profession by summarising recent studies within the "technological turn" of Translation Studies. They show that the influence of technology on translation is twofold: on the one hand, it can help to streamline production processes and increase productivity; on the other hand, it can have a negative impact on the translation process, both as regards the cognitive process (segmentation, which makes the translator lose the overall view of the text) as well as the business process (with clients demanding lower prices and the translator appearing as the last link in a long supply chain).

Earlier research reports both positive and negative perceptions of translation technology by translators. According to translators in LeBlanc's $(2013,2017)$ ethnographic study, TMs increase productivity, decrease monotonous work, and help to create consistency in terminology and expressions. Similar aspects were reported by Marchman (2014), who also mentions increased access to data that helps in finding translation solutions, the possibility to analyse the text to be translated, predict the time it takes to translate it and justify the cost to clients. However, at the same time, the tools make 
translating more mechanical when all one does is accept $100 \%$ matches: the solutions from the TM influence the translator's thinking and focussing on one segment at a time makes it more difficult to see the whole, which may lead to less cohesive expression. In addition, productivity demands increase stress. Similarly, the analysis made by Koskinen and Ruokonen (2017) of 106 love and hate letters related to technology, written by translators or translation students, indicates that translation technology is considered a central and mainly positive aspect of translators' work, although translators dislike nonfunctioning technology and poor usability. In the study, they used a method borrowed from usability studies where participants were asked "to write a short love letter/breakup letter' to the tool, application or aspect of work of their choice" (Koskinen \& Ruokonen, 2017: 9). Of the 106 letters, they classified 59 as love letters, 40 as break-up letters and 7 as ambivalent (containing both positive and negative attitudes). Among the 59 love letters, 18 mentioned translation technology (such as TM software), and among the breakup letters, 13 (Koskinen \& Ruokonen, 2017: 14-15). Similar mixed attitudes towards translation technology were found by Moorkens (2020: 66) in his survey of governmentaccredited Irish translators: a question related to MT gave 15 positive and 22 negative comments. On post-editing, 12 comments were positive and 15 negative, but "many did not understand the concept" (idem).

A different approach to studying translation technology perception was taken by Vieira (2020), who analysed a corpus of 2 million words collected from professional translators' blogs and discussion forums. In his qualitative analysis of 50 postings containing the keywords "rate" and "machine translation", he used a more refined classification than positive vs. negative and was able to connect technology use to market practices. In fact, the translators' comments were less negative towards MT itself, but instead, they criticized market practices: downward pressure from agencies or clients appeared as the second most frequent classification (14 instances) of "rate", and 6 postings mentioned the "negative impact of CAT, MT and/or TM discount structure" (Vieira, 2020: 13-14). Both Vieira (2020) and Moorkens (2020) draw attention to the threats imposed by translation technology on the translation profession. For the Irish translators in Moorkens' survey, the main threats were falling translation quality, low rates and MT replacing human translators. According to Vieira (2020), MT is not a threat in itself, but the business practices associated with its use are. Vieira (2020: 16), therefore, argues that translation technology "cannot be decoupled from its market reverberations and economic effects."

Dillon and Fraser (2006) surveyed the adoption of TM software among UK-based professional translators. Although the study describes a technological landscape that has changed completely over the years - with the development of TM software, other CAT tools and MT - it is interesting because of the methodology used to study the perception of translation technology. In their survey, Dillon and Fraser (2006) applied the Technology Acceptance Model (TAM), originally developed by Moore and Benbasat (1991). The TAM is one of the most well-known models ${ }^{1}$ in information systems research, developed to analyse and predict how users adopt information technology. It was designed to "measure

1 For more information on its influence, see Hirschheim, 2007, and articles in the special issue. 
users' perceptions of adopting an information technology innovation" (Moore \& Benbasat, 1991: 193).

In their survey, Dillon and Fraser (2006) used 24 statements related to TM use, based on the list of items presented by Moore and Benbasat (1991: Appendix 3). Their results showed that translators using TMs were more positive towards their use than translators who did not use a TM (Dillon \& Fraser, 2006). The TM users were those with 10 or more years of translating experience; the users with 3 years or less of translating experience had little or no experience with TMs. More recently, it is the younger translators that seem more likely to be familiar with translation technology (cf. Krüger 2016: 114-115). The results of a survey on the ICT skills of Finnish translators conducted in 2012-2013 (Suppanen, 2015, Mikhailov, 20152) showed that younger respondents were more familiar with translation technology than older respondents, and that respondents who had studied translation at university evaluated their IT skills (in word processing, using CAT tools and information-seeking on the Internet) higher than respondents with other types of education. However, although TMs have been in use by professionals since the early 2000's, their use has only been part of compulsory courses in translator education in Finland since the early 2010's (Suppanen, 2015: 28-33), and the use of MT for professional purposes is even more recent. According to Suppanen's survey (2015: 54), even the younger respondents who had been taught the basics of translation technology at the university said they had learned to use the tools after graduation, in continuous education or at work in informal settings. Informal education is defined by H. Salmi (2012: 47) as "education given by different institutes whose first function is not to educate", such as media, libraries, peer groups or self-education. Recent translation competence models, however, do tend to include the use of translation technology (e.g., the EMT Competence Framework, European Commission, 2017), and CAT tools are being increasingly adopted in the curricula of translator education programmes (Rothwell \& Svoboda, 2019).

Another model designed for surveying technology perception is the NEMP model (New Educational Models or Paradigms), originally developed for evaluating ICT-based activities (Hernant, 2003). This model has been used in education sciences to study how schoolteachers and trainee teachers perceive the use of ICT solutions and Augmented Reality (H. Salmi, 2012; H. Salmi et al., 2012). The model is a questionnaire with 27 statements grouped in three sections: the role of ICT, the changes it brings about and its innovative aspects. The statements describe the phenomenon in a general manner, such as "ICT as a tool" or "organisational changes", in order to be generalisable in different contexts. According to H. Salmi (2012), the use of the NEMP tool presupposes that the respondents are familiar with the subject field that is studied and the ability to generalise. Professional teachers and trainee teachers were such a target group for $\mathrm{H}$. Salmi et al. (2012), who studied their perception of new tools. In their experiment, physics was taught to secondary school pupils by making normally invisible physical phenomena (such as thermal motion or wing dynamics) visible using Augmented Reality technology.

2 The survey was conducted as part of Outi Suppanen's Master's Thesis at the University of Tampere. The thesis was supervised by Mikhail Mikhailov, and the results have been reported both in Suppanen's Master's thesis and in Mikhailov's article. 
The main results indicated that the NEMP tool was useful for monitoring the perception of new tools such as the Augmented Reality technology.

\section{Materials and methods}

The data discussed in this article comes from two surveys: one the author administered to translation students in 2011-2014 (already reported in L. Salmi, 2014) and one administered to professional translators in 2014. Both surveys contained a section with statements related to translation technology. The data contains 450 responses to these statements from the professional translators and 165 responses from the translation students. This section describes how the data from the professional translators was collected and how the questions related to translation technology were formulated.

The survey distributed to professional translators was conducted in 2014, with Minna Ruokonen as the principal investigator, and Tiina Tuominen, Taru Virtanen and the author of this article as collaborating researchers. The focus of the survey was to study how professional translators in Finland perceive the status of the translator's profession: defined as "the prestige and value of the translation profession in general" as well as "the prestige and value of an individual translator's work" (Ruokonen \& Mäkisalo, 2018: 3). The questionnaire partly replicated Helle V. Dam's and Karen Korning Zethsen's (2008, 2011) status surveys among translators in Denmark, and a section related to translation technology was added by the present author. The survey was an online questionnaire distributed at the end of 2014 via two major translator associations in Finland, as well as through social media, after having been tested by three professional translators. The present article is the fourth publication reporting on the collected data. The results of the status perceptions have been reported by Ruokonen and Mäkisalo (2018); they indicate that Finnish translators perceive the general status of translators, in terms of how appreciated they are in the Finnish society, as middling (2.55 on a scale of 1 to 5), but regard their own work as highly appreciated (3.94 on a scale of 1 to 5). Partial analyses of the data can also be found in Ruokonen (2018) concerning translators authorised to produce legally valid translations, and in Virtanen (2019) concerning government-employed translators.

As a pilot to the survey distributed to professionals, a survey on the perception of translation technology by translation students was conducted by the author (L. Salmi 2014) in the years 2012-2014. The pilot survey was part of a regular course evaluation questionnaire that was used to collect feedback from translation technology courses held at the Universities of Turku and Eastern Finland.

The NEMP model was chosen to study the perception of translation technology in both the students' and the professionals' survey, as it had been proven to function in earlier studies related to the perception of ICT. Both questionnaires contained 30 statements, grouped into three subsections: 1) the role of translation technology in translating, 2) the changes it brings about in translation work, and 3) its innovative aspects. The statements were adapted from those originally used by Hernant (2003), $\mathrm{H}$. 
Salmi (2012) and H. Salmi et al., 2012, and were formulated to reflect the use of translation technology in a similarly general and neutral manner.

The statements used are listed in tables 2, 3 and 4 below. The respondents were asked to select the extent to which they agreed with each statement on the Likert scale. The options ranged from 1 (fully disagree) to 5 (fully agree). In adapting the statements from those used by H. Salmi (2012), learning contexts were replaced by translating contexts. Statements such as the ICT's role as a "provider of feedback" or as a "media" were kept, and in some statements, just the idea of translating was added: "tool", for example, was changed to "translator's tool" (Table 2). In some cases, bigger changes were necessary, as when "pedagogical changes" was replaced by "it changes the nature of translating", or when changes in the "roles and responsibilities of teachers/pupils" was replaced by those of "clients/translators" (Table 3). Two statements were left out. Three statements were added, namely "It broadens one's personal abilities", "It develops the translator's professional skills" and "It facilitates learning at work" (Table 3). It must be noted that in the earlier studies (H. Salmi, 2012; H. Salmi et al, 2012, L. Salmi, 2014) as well as in this one, the statements on the questionnaire were given in Finnish, and they have been translated into English here by the author.

\section{Results}

This section presents the professional translators' background data, reports their responses to the 30 statements by type of employment and by specialisation, and presents the statistical analyses used in connection with the NEMP model. The statement results are compared with the results of the survey with translation students (L. Salmi 2014).

\subsection{Background information}

The background data of the 450 professional translator respondents is presented in detail by Ruokonen and Mäkisalo (2018: 6-8). In summary, the majority (80\%) of the respondents were female $(\mathrm{N}=362)$ and business translators $(60 \%)$. "Business translator" refers here, in contrast to "literary translator", to translators of non-fiction texts, whether they are specialized in business, legal, technical or any other field of translation. $30 \%$ of the respondents were aged between 35 and 44, 25\% between 45 and 54, and 22\% were 55 or older. Freelancers and self-employed translators represented $58 \%$ of the respondents, while 30\% were employees and 12\% otherwise occupied (unemployed, studying, or working in a field other than translation).

As background information, the survey also asked the respondents, on a scale from 1 to 5 , to give an estimate on their ability to use various ICT tools and services or select the option indicating they did not use the tool or service in question. The items listed were word processors, spreadsheets, presentation graphics, using the Internet in information seeking, library services and databases, translation memories, subtitling software, quality assurance tools and project management software. The list did not contain MT, as at the time of conducting the survey, 2014, the quality of the MT systems 
including Finnish was only sufficient to suggest ideas for expressions or not usable at all (European Commission trials reported by Leal Fontes, 2013: 11). MT was not at that point considered an important tool by Finnish professional translators (Mikhailov, 2015).

As for the use of word processors, the great majority (437 respondents / 97\%) estimated their skills to be excellent or good (average: 4.49), and the same was true for information retrieval skills (447 respondents / 99\%), but for TM tools the average was 3.71. Table 1 presents the responses related to TMs by respondents' specialisation (business/non-fiction translation, audio-visual translation, literary translation and other) and by their type of employment (employed, freelancer and otherwise occupied):

\begin{tabular}{|c|c|c|c|c|c|c|c|c|c|}
\hline & \multicolumn{2}{|c|}{ All } & \multicolumn{4}{|c|}{ Specialisation } & \multicolumn{3}{|c|}{ Type of employment } \\
\hline & & & Business & AV & Literary & Other & Employed & Freelancer & Other \\
\hline & $\mathrm{N}$ & $\%$ & $N$ & $N$ & $N$ & $N$ & $N$ & $N$ & $N$ \\
\hline $\begin{array}{l}\text { Very } \\
\text { good=5 }\end{array}$ & 96 & 21.3 & 85 & 1 & 0 & 10 & 41 & 49 & 6 \\
\hline Good $=4$ & 135 & 30 & 113 & 7 & 1 & 14 & 58 & 68 & 9 \\
\hline Average $=3$ & 70 & 15.6 & 42 & 9 & 9 & 10 & 14 & 40 & 16 \\
\hline $\mathrm{Bad}=2$ & 24 & 5.3 & 4 & 9 & 6 & 5 & 5 & 14 & 5 \\
\hline Very bad $=1$ & 27 & 6 & 6 & 4 & 11 & 6 & 5 & 20 & 2 \\
\hline $\begin{array}{c}\text { Not } \\
\text { applicable }\end{array}$ & 98 & 21.8 & 19 & 27 & 36 & 16 & 14 & 69 & 15 \\
\hline Total & 450 & 100 & 269 & 57 & 63 & 61 & 137 & 260 & 53 \\
\hline Average & 3.71 & & 4.07 & 2.73 & 2.00 & 3.38 & 4.02 & 3.59 & 3.32 \\
\hline
\end{tabular}

Table 1. Self-assessment of TM skills, by employment type and specialisation

Table 1 shows that business translators and literary translators represent nearly opposites as to their self-assessed skills: the average score of the business translators on the scale of 1 to 5 is 4.07, and the majority of them (198 of 269) estimate their skills as good or very good, while the average for the literary translators who have answered this question is 2, and the "Not applicable" row indicates that over a half do not use TMs at all. There are also some differences between employed translators, freelance translators and others. The employed translators had the highest average score (4.02) while $34 \%$ of the freelance translators did not respond to the question. 


\subsection{Responses to the 30 statements}

The respondents' perception of language and translation technology (LTT) was measured using the 30 statements, grouped into three subsections in the survey questionnaire:

1. What is the role of LTT in the translator's work?

2. How does LTT change the translator's work, compared to a situation where a translator is not using any translation memories, spelling checkers or corpora, for example?

3. How does LTT renew translating?

A specific definition of LTT was not provided, and it was left for the respondents to decide what tools they would include in LTT. The list of software and services in the previous question (Table 1) contained examples of translator's tools, and some examples were mentioned in the second subsection (Table 3).

The average scores are presented in tables 2, 3 and 4 for each subsection, with both the average for the whole group and averages grouped by the respondents' specialization $(\mathrm{B}=$ business translation, $\mathrm{AV}=$ audio-visual translation, $\mathrm{L}=$ literary translation, and $\mathrm{O}=$ otherwise occupied) and by their type of employment $(E=$ employed, $F L=$ freelancer, and $\mathrm{O}=$ other). The statements are presented in the tables in descending order, with the highest average of the whole group listed first.

The responses to the statements in the first subsection (Table 2) show that the broad concept of LTT was deemed above all to play the role of a concrete tool of translation production (a translator's tool) ${ }^{3}$, as well as a repository providing information and background material for the translation work.

\begin{tabular}{|c|c|c|c|c|c|c|c|c|}
\hline \multicolumn{1}{|c|}{} & \multicolumn{3}{|c|}{ Specialisation } & \multicolumn{3}{|c|}{ Employment } \\
\hline $\begin{array}{c}\text { Statement: Language and translation } \\
\text { technology works well... }\end{array}$ & All & B & AV & L & O & E & FL & O \\
\hline as a translator's tool & 4.16 & 4.46 & 4.05 & 3.14 & 3.98 & 4.39 & 4.01 & 4.17 \\
\hline as an information bank & 3.87 & 4.12 & 3.47 & 3.19 & 3.89 & 4.18 & 3.93 & 4.09 \\
\hline $\begin{array}{c}\text { as a shared background material } \\
\text { repository }\end{array}$ & 3.73 & 3.95 & 3.44 & 3.05 & 3.72 & 4.05 & 3.85 & 4.23 \\
\hline as a framework for translation work & 3.62 & 3.85 & 3.61 & 2.84 & 3.44 & 3.87 & 3.63 & 3.64 \\
\hline $\begin{array}{c}\text { as a connector between different CAT } \\
\text { tools }\end{array}$ & 3.59 & 3.81 & 3.35 & 3.00 & 3.43 & 3.62 & 3.51 & 3.49 \\
\hline as a platform for information exchange & 3.27 & 3.35 & 3.14 & 2.94 & 3.39 & 3.74 & 3.37 & 3.53 \\
\hline as a provider of feedback & 2.90 & 2.91 & 2.88 & 2.78 & 3.05 & 3.64 & 3.25 & 3.30 \\
\hline as a model and simulator for translation & 2.80 & 2.87 & 2.65 & 2.59 & 2.87 & 3.53 & 3.24 & 3.30 \\
\hline as a tool for communication & 2.78 & 2.70 & 2.88 & 2.89 & 2.93 & 3.19 & 3.28 & 3.43 \\
\hline
\end{tabular}

Table 2. The role of LTT, showing averages on a scale from 1 to 5 , by specialisation and type of employment

In Table 2, values grouped by the respondents' specialisation show that business translators had the highest scores in nearly all the statements. These professional

3 The word used in the questionnaire for 'tool' in Finnish was työväline, a composite word formed from työ = 'work' and väline = 'tool', 'instrument' or 'device'. In the context above, this word has more concrete and possibly narrower connotations than the word 'tool' in English. 
translators' scores are all lower than the scores given by translation students surveyed in 2012-2014, ranging from 4.53 (translator's tool) to 2.97 (provider of feedback) (L. Salmi, 2014: 58). Like professional translators, the students gave the highest score to LTT as a translator's tool, but otherwise the order of statements differed slightly. The statements in the student survey also differed in that the student survey contained a statement related to teaching, "works well as a tool for teaching translation" (L. Salmi, 2014: 58, Appendix 1). This statement was left out of the survey distributed to professionals.

\begin{tabular}{|c|c|c|c|c|c|c|c|c|}
\hline & & \multicolumn{4}{|c|}{ Specialisation } & \multicolumn{3}{|c|}{ Employment } \\
\hline $\begin{array}{l}\text { Question: How does language and } \\
\text { translation technology change a } \\
\text { translator's work, compared to a situation } \\
\text { where a translator is not using any } \\
\text { translation memories, spelling checkers or } \\
\text { corpora, for example? }\end{array}$ & All & B & AV & $\mathrm{L}$ & 0 & $E$ & $\mathrm{FL}$ & 0 \\
\hline $\begin{array}{c}\text { It changes the computerised working } \\
\text { environment }\end{array}$ & 4.14 & 4.38 & 3.82 & 3.41 & 4.15 & 4.39 & 4.01 & 4.17 \\
\hline It changes translating in practice & 4.02 & 4.22 & 3.79 & 3.32 & 4.11 & 4.18 & 3.93 & 4.09 \\
\hline It changes the working culture & 3.95 & 4.10 & 3.72 & 3.43 & 4.05 & 4.05 & 3.85 & 4.23 \\
\hline It changes the nature of translating & 3.71 & 3.85 & 3.54 & 3.21 & 3.74 & 3.87 & 3.63 & 3.64 \\
\hline $\begin{array}{l}\text { It puts more emphasis on technical } \\
\text { innovations }\end{array}$ & 3.54 & 3.67 & 3.40 & 3.13 & 3.54 & 3.62 & 3.51 & 3.49 \\
\hline It broadens one's personal abilities & 3.50 & 3.63 & 3.40 & 2.92 & 3.61 & 3.74 & 3.37 & 3.53 \\
\hline $\begin{array}{l}\text { It develops the translator's professional } \\
\text { skills }\end{array}$ & 3.37 & 3.52 & 3.19 & 2.83 & 3.44 & 3.64 & 3.25 & 3.30 \\
\hline It facilitates learning at work & 3.34 & 3.48 & 3.16 & 2.81 & 3.41 & 3.53 & 3.24 & 3.30 \\
\hline $\begin{array}{c}\text { It changes the roles and responsibilities } \\
\text { of translators }\end{array}$ & 3.27 & 3.37 & 3.14 & 2.90 & 3.33 & 3.19 & 3.28 & 3.43 \\
\hline $\begin{array}{c}\text { It changes the roles and responsibilities } \\
\text { of the client }\end{array}$ & 3.06 & 3.06 & 3.12 & 2.81 & 3.28 & 2.74 & 3.18 & 3.34 \\
\hline
\end{tabular}

Table 3. Change brought to translation work by LTT, showing averages on a scale from 1 to 5 , by specialisation $(B=$ business translation, $A V=$ audio-visual translation, $L=$ literary translation, and $O=$ otherwise occupied) and type of employment ( $E=$ employed, $F L=$ freelancer, and $O=$ other)

The responses to the statements in the second subsection, on the changes brought about by LTT (Table 3), indicate that LTT changes the work on a practical level, as well as the nature of translating and the whole working culture:

Values grouped by the respondents' specialization show that business translators had the highest scores in all but one statement. The change in the roles and responsibilities of translators and clients was considered less important than the other types of changes. The respondents in both "other" groups put slightly more emphasis on the change in the client's roles.

Compared to translation students surveyed in 2012-2014 (L. Salmi, 2014: 59), the professionals' scores were lower in this subsection as well: the students' scores ranged from 4.29 (change in the computerised working environment) to 3.42 (change in the roles and responsibilities of the client), but, again, there were some differences in the order. In order to clarify the statement on the nature of translating, formulated in a more 
ambiguous manner in the student survey (L. Salmi, 2014: 59, Appendix 1), the wording of the statement was slightly different in the professionals' questionnaire.

In the third subsection, concerning the innovative role of LTT (Table 4), the respondents agreed with the statements that LTT makes translating faster and more cost-efficient, but disagreed on the increase of creativity and the social contacts:

\begin{tabular}{|c|c|c|c|c|c|c|c|c|}
\hline & & \multicolumn{3}{|c|}{ specialisation } & \multicolumn{3}{c|}{ employment } \\
\hline $\begin{array}{c}\text { Question: How does } \\
\text { language and translation } \\
\text { technology renew } \\
\text { translating? }\end{array}$ & All & $\mathrm{B}$ & $\mathrm{AV}$ & $\mathrm{L}$ & $\mathrm{O}$ & $\mathrm{E}$ & $\mathrm{FL}$ & $\mathrm{O}$ \\
\hline $\begin{array}{c}\text { It speeds up the } \\
\text { translator's work. }\end{array}$ & 3.99 & 4.29 & 3.72 & 3.21 & 3.77 & 4.39 & 3.82 & 3.85 \\
\hline $\begin{array}{c}\text { It increases the cost- } \\
\text { efficiency of the } \\
\text { translator's work. }\end{array}$ & 3.81 & 4.09 & 3.53 & 3.08 & 3.61 & 4.24 & 3.60 & 3.75 \\
\hline $\begin{array}{c}\text { You can use LT to divide } \\
\text { workload between several } \\
\text { translators. }\end{array}$ & 3.44 & 3.64 & 3.18 & 2.75 & 3.49 & 3.86 & 3.21 & 3.45 \\
\hline $\begin{array}{c}\text { It provides more } \\
\text { possibilities for comparing } \\
\text { different options. }\end{array}$ & 3.44 & 3.54 & 3.39 & 2.94 & 3.54 & 3.75 & 3.28 & 3.34 \\
\hline $\begin{array}{c}\text { It facilitates getting started } \\
\text { with translation work more } \\
\text { independently. }\end{array}$ & 3.20 & 3.33 & 3.35 & 2.56 & 3.13 & 3.47 & 3.07 & 3.13 \\
\hline $\begin{array}{c}\text { It provides contextual } \\
\text { information. }\end{array}$ & 3.08 & 3.09 & 3.04 & 2.97 & 3.18 & 3.22 & 3.02 & 3.02 \\
\hline $\begin{array}{c}\text { It makes it easier to } \\
\text { understand the content of } \\
\text { the text being translated. }\end{array}$ & 2.79 & 2.78 & 2.98 & 2.63 & 2.80 & 2.85 & 2.75 & 2.83 \\
\hline It facilitates networking. & 2.56 & 2.49 & 2.54 & 2.81 & 2.61 & 2.67 & 2.49 & 2.58 \\
\hline $\begin{array}{c}\text { It increases the } \\
\text { appreciation of translators' } \\
\text { work. }\end{array}$ & 2.44 & 2.49 & 2.32 & 2.29 & 2.46 & 2.63 & 2.33 & 2.45 \\
\hline $\begin{array}{c}\text { It makes the translator's } \\
\text { work more creative. }\end{array}$ & 2.26 & 2.19 & 2.35 & 2.30 & 2.44 & 2.33 & 2.26 & 2.08 \\
\hline $\begin{array}{c}\text { It enhances the } \\
\text { translator's sociability }\end{array}$ & 2.25 & 2.15 & 2.25 & 2.51 & 2.38 & 2.22 & 2.27 & 2.21 \\
\hline
\end{tabular}

Table 4. The innovative role of $L T T$, showing averages on a scale from 1 to 5 , by specialisation $(B=$ business translation, $A V=$ audio-visual translation, $L=$ literary translation, and $O=$ otherwise occupied) and type of employment ( $E=$ employed, $F L=$ freelancer, and $O=$ other)

Here, the highest scores were given by employed translators: all their scores but one were above the average for all respondents. Creativity and sociability were perceived as the least connected with LTT. Again, the scores given by students were higher, ranging from 4.35 (speeding up translator's work) to 2.40 (making work more creative) (L. Salmi, 2014: 60). Scores for sociability and creativeness were lowest in both surveys. The student survey did not contain the statement on increasing the appreciation of translator's work, and the statement on contextual information was expressed in a more ambiguous 
manner (L. Salmi, 2014: 60, Appendix 1), which was why the wording was changed for the professionals' survey.

\subsection{Comments on the 30 statements}

The LTT section ended with an open question where respondents could comment on anything related to the 30 statements. Altogether 119 comments were given, 53 by business translators, 29 by literary translators, 23 by others and 14 by AV translators. They commented on the questions per se, explained their choices or reflected on the changes brought about by LTT. Eighteen literary translators mentioned that they do not use translation technology or TMs, and 3 said they do not even know what LTT refers to. It is interesting to note that some of the comments from business translators or from others were exactly the opposite: 6 respondents commented that translation technology is indispensable or that they could not imagine working without it. Three respondents commented that CAT tools have always been there during the time they have worked as translators, so they have difficulties imagining translating without them. For audiovisual translators, the majority of whom in Finland work with subtitling, the answers slightly differed from the other respondents: 6 out of 14 comments mentioned they do not use any other translation technology than software for subtitling. Machine translation was mentioned by 6 respondents only, all of them mentioning the poor quality of the engines with a language like Finnish.

Positive comments mentioned that LTT speeds up and facilitates translating (8 respondents) is a good tool in general, makes it easy to divide workload and brings consistency. Negative comments said that LTT decreases or does not raise the appreciation of the profession (9 respondents), and that the use of technology forces translators to lower rates and clients expect them to work faster ( 5 respondents). As for cognitive aspects, respondents mentioned that the use of TM makes it more difficult to see the whole text and come up with other solutions than those given by the TM. Three respondents mentioned that LTT makes the translator's work less creative and that LTT does not have much to do with sociability. A number of respondents brought up both good and bad sides, mentioning that some of the TM software is brilliant, some awful, or reflected that TM systems make it easy to divide projects among several translators, but such a division may also make the resulting translation less consistent and necessitate more revision work. Respondent 45 summarized the advantages and disadvantages nicely by saying: "The new technology is a good servant but a bad master" (translated from Finnish by the author).

\subsection{Statistical analyses}

Statistical analyses on the data were conducted by using exploratory factor analysis and one-way analysis of variance (ANOVA) ${ }^{4}$.

4 I wish to thank by Paul Thuneberg (University of Helsinki) for doing the statistics. 
Factor analysis is a collection of statistical methods that is used to explain correlations among several variables in data, with the goal of summarizing "complicated patterns of correlations between variables into a simpler explanatory framework" (Cudeck, 2000: 294). The analysis calculates correlations in the data (in this case the responses to the 30 statements), and factors emerge (load) from these sets of correlations.

The exploratory factor analysis was carried out using the principal axis method. The commonality values of all variables were higher than 0.20 , and no variables were removed. The factor matrix was rotated using several different rotations, of which direct oblimin rotation produced the clearest results. In the factor analysis, five factors emerged. The number of factors was determined by using Cattell's scree plot. The factors were named using the top loading variables of each factor as follows:

F1 - Efficiency (LTT as an efficient tool)

F2 - Sociability (LTT as a tool for networking and providing context)

F3 - Working culture (changes in the translator's work)

F4 - Communication (LTT as a tool for communication)

F5 - Learning (LTT as a tool for enhancing the translator's professional development)

The complete table of factors, with the sets of statements correlating with each other and thus forming a factor, is presented in the Appendix.

The analysis of variance was done by comparing the scores given in the statements by different respondent groups (representing variables, e.g., age, specialisation or work experience in years) and calculating whether the differences are statistically significant. In the following, the relevant statistically significant differences between respondent groups are presented by factor.

For the Efficiency factor (F1), LTT was perceived efficient more often by business translators than by other specializations, and this difference was statistically significant $(F(3,449)=31, p<0.001)$. Literary translators gave lower scores than the other groups in the statements connected to F1. Other explaining variables were age and working experience: younger translators (less than 35 years of age, $\mathrm{N}=104$ ) perceived LTT as more efficient than older translators (over 45 years of age, $\mathrm{N}=213$ ), and translators with more than 20 years of translating experience perceived LTT as less efficient than translators with less than 10 years of translating experience. This correlates with the student survey (L. Salmi 2014), where students with working experience in translating had a more sceptical view of translation technology than those with less or no working experience.

For the Sociability factor (F2), statistically significant differences only emerged between two small groups on the basis of education: respondents with a licentiate ${ }^{5}$ or doctoral degree $(\mathrm{N}=8)$ gave higher than average scores for the statements grouped within this

5 A licentiate's degree is a research degree completed after a master's degree and before a doctorate. 
factor, but the difference was statistically significant only compared to respondents with a diploma in translation ${ }^{6}(\mathrm{~N}=22)(\mathrm{F}(5,449)=3, \mathrm{p}<0.001)$.

For the Working culture factor (F3), specialization was an explaining variable with a statistically significant difference $(F(3,449)=13, p<0.001)$ : business translators perceived the change brought about by LTT in the working culture as more important than other specialisations. There was also a statistically significant difference between translators residing in Finland and those living abroad $(N=58)(F(1,449=5, p<0.05)$ : the latter perceived the change as more important. The values of literary translators were significantly lower than those of the other specializations.

For the Communication factor (F4), translators who were younger than 45 differed from older translators: they perceived LTT's role in communication as more significant. The values of literary translators were significantly lower than those of the other specialisations.

For Learning (F5), translators over 60 experienced the importance of LTT in learning to be smaller than the other groups. Here, again, the values of literary translators were significantly lower than those of the other specialisations.

\section{Discussion}

The 5 factors that loaded in the factor analysis (efficiency, sociability, working culture, communication and learning) did not directly correspond to the 3 subsections in the questionnaire, as has been the case in previous research using the NEMP model $(\mathrm{H}$. Salmi, 2012, H. Salmi et al., 2012). In spite of this, the results show that language and translation technology is perceived by professional translators as an efficient translator's tool that has changed practices in translating and is a matter of continuous learning.

As the statements related to change (Table 3) were consciously formulated in a neutral manner, the translators were not asked if the change was for better or for worse. The responses to the open question (section 4.3), however, show that the changes in the working culture are seen as both positive and negative by the translators, as was also noted by Alonso and Vieira (2021). Similar to LeBlanc's $(2013,2017)$ and Marshman's (2014) studies, the use of LTT increases productivity, decreases monotonous work, and helps to create consistency in terminology and expressions, but, at the same time, makes translating more mechanical and more difficult to see the text as a whole. Altogether 11 answers contained a comment that discussed both the advantages and the disadvantages of LTT.

Previous surveys on the use of translation technology have indicated that translators who use translation technology have a more positive perception of it than those who have no or little experience in using it (Dillon \& Fraser, 2006). Dillon and Fraser (2006) had designed their questionnaire for two different groups, the users and the non-users of TMs. This was not the case in this study, but the two groups are visible when looking at the self-estimates in TM use in Table 1: the majority of business translators (240 out

6 This refers to translators trained in Language Institutes in Finland from 1966 to 1981, before the training was incorporated into universities. 
of 269) have estimated their skills as very good, good or average, whereas most of the literary (53 out of 63) and audio-visual (40 out of 57) translators said their skills were bad or very bad or did not give an estimate at all. The average for all respondents was 3.71, which is similar to Suppanen's and Mikhailov's survey, where the average was 3.36 (Suppanen, 2015: 46). All in all, business translators seemed to have a more positive perception of translation technology than audio-visual and literary translators. This is also visible in the scores presented in Tables 2 and 4: the business translators gave higher scores in most of the statements where LTT is considered to work well, or to facilitate or enhance translator's work in some way.

As for efficiency (F1), LTT was perceived as efficient especially by business translators who were younger than 35 years old and had less than 10 years of translating experience. Translators with more than 20 years of translating experience perceived LTT as less efficient. This seems to correlate with the student survey (L. Salmi 2014), where students, in general, evaluated the statements grouped in this factor higher than the professionals, and students who had working experience in using translation technology had a more sceptical perception of the tools. Suppanen (2015: 64) suggests that students who have used the tools only in a classroom setting may not have seen all the problems encountered in working life use with a longer duration.

As for the limits of the study, it would have been useful to give a precise definition of LTT and differentiate LTT users and non-users by adding to each NEMP statement a "not applicable" option that the respondents who found the statement irrelevant could have selected. As mentioned, the NEMP model presupposes familiarity with the subject matter, but this clearly was not the case for all the respondents for all the statements. Some respondents commented that some statements used in the questionnaire were abstract or difficult to understand, such as LTT being a model and a simulator, or less relevant for translation work, such as "provider for feedback". This was done on purpose, as explained above, but as some of the statements modified for use in the translation context were rather practical, this is a fair criticism. If the NEMP model is used in future surveys, an explanatory note on the nature of the statements could be added. Another limitation is that the data was collected in 2014. Reporting it now is nevertheless justified by the fact that not many similar surveys have been conducted.

\section{Conclusion}

This paper has described professional translators' $(\mathrm{N}=450)$ perceptions of translation technology and introduced a survey tool that can be used to study the perception of such changes (the NEMP model). The NEMP model proved to be useful in providing statements to use when studying the perception of the role and influence of technology and the changes it brings about. The survey showed that LTT is predominantly used by business translators, and that LTT is perceived by professional translators as an efficient tool that has changed their practices and working culture. The nature of the changes was not the focus in this survey, but results indicate a twofold perception similar to earlier studies: the positive sides include efficiency and consistency in expression, the negative sides fragmentation of the text, lowering rates and increasing stress. 
As mentioned, some of the statements used in the questionnaire were perhaps too abstract. Future work could include testing a modified list of statements, where the less concrete statements have been clarified. The survey statements could also be revised by placing more emphasis on the change translation technology has brought and its positive and negative effects, including translators' concerns about the "market reverberations and economic effects" described by Vieira (2020: 16).

Will the use of translation technology and especially MT continue to be seen as a threat that diminishes the appreciation of the profession, lowers pay rates and hinders creative expression in the target language, as respondent 202 put it in their comment? Or, as TMs and MT are already integrated into every translation workflow, will they cease to be considered separate tools at all? Vieira (2020: 2) reminds us that seeing new technology as a threat is not a new phenomenon, and Alonso and Vieira (2021: 399) take a more positive stand in suggesting an interactive, creative role for the future translator. For the time being, we can only agree with respondent 45, for whom the new technology was "a good servant but a bad master".

\section{References}

Alonso, E.; Vieira, L. N. (2021). The impact of technology on the role of the translator in globalized production workflows. In: Bielsa, E.; Kapsaskis, D. (eds.). The Routledge handbook of translation and globalization. London, New York: Routledge, pp. 391405.

Bowker, L.; Fisher, D. (2010). Computer-aided translation. In: Gambier, Y.; Van Doorslaer, L. (eds.). Handbook of Translation Studies, Volume 1. Amsterdam: John Benjamins, pp. 60-65. 〈https://doi.org/10.1075/hts.1.comp2〉. [Accessed: 20211115].

Cudeck, R. (2000). Exploratory Factor Analysis. In: Tinsley H. E. A.; Brown, S. D. (eds.). Handbook of Applied Multivariate Statistics and Mathematical Modeling. San Diego: Academic Press, pp. 265-296. 〈https://doi.org/10.1016/B978-012691360-6/50011-2〉. [Accessed: 20211115].

Dam, H. V.; Zethsen, K. K. (2008). Translator status: A study of Danish company translators. The Translator, v. 14, n. 1, pp. 71-96. 〈https://www.tandfonline.com/doi/abs/10.1080/13556509.2008.10799250〉. [Accessed: 20211115].

Dam, H. V.; Zethsen, K. K. (2011). The Status of professional business translators on the Danish market: a comparative study of company, agency and freelance translators. Meta, Translators' Journal, v. 56, n. 4, pp. 976-997. 〈https://doi.org/10.7202/1011263ar〉. [Accessed: 20211115].

Dillon, S.; Fraser, J. (2006). Translators and TM: An investigation of translators' perceptions of translation memory adoption. Machine Translation, n. 20, pp. 67-79, 〈https://doi.org/10.1007/s10590-006-9004-8>. [Accessed: 20211115].

European Commission (2017). European Master's in Translation: Competence Framework 2017. 
〈https://ec.europa.eu/info/sites/info/files/emt_competence_fwk_2017_en_web.pdf〉. [Accessed: 20210202].

European Language Industry Survey (2020). PDF slides available at: 〈https://ec.europa.eu/info/departments/translation/language-industry-platformlind_en〉. [Accessed: 20210516].

Hernant, C. (2003). Does mastery of ICT really improve pupil performance? Revista Lanbide, n. 22, pp. 42-44. 〈http://www.slideshare.net/HETELFP/revista-lanbide-2003〉. [Accessed: 20210620].

Hirschheim, R. (2007). Introduction to the Special Issue on 'Quo Vadis TAM: Issues and Reflections on Technology Acceptance Research'. Journal of the Association for Information Systems, v. 8, n. 4, pp. 203-205. 〈https://doi.org/10.17705/1jais.00128〉. [Accessed: 20211115].

Koskinen, K.; Ruokonen, M. (2017). Love letters or hate mail? Translators' technology acceptance in the light of their emotional narratives. In: Kenny, D. (ed.). Human issues in translation technology. Oxon/New York: Routledge, pp. 8-24.

Krüger, R. (2016). Contextualising Computer-Assisted Translation Tools and Modelling Their Usability. Trans-kom, v. 9. n. 1, pp. 114-148. 〈http://www.transkom.eu/bd09nr01/trans-kom_09_01_08_Krueger_CAT.20160705.pdf〉. [Accessed: 20210620].

Leal Fontes, H. (2013). Evaluating machine translation: Preliminary findings from the first DGT-wide translators' survey. Languages and Translation, n. 6, pp. 10-11.

LeBlanc, M. (2013). Translators on translation memory (TM): Results of an ethnographic study in three translation services and agencies. Translation \& Interpreting, v. 5, n. 2, pp. 1-13. 〈https://doi.org/10.12807/ti.105202.2013.a01〉. [Accessed: 20211115].

LeBlanc, M. (2017). “I can't get no satisfaction!": Should we blame translation technologies or shifting business practices? In: Kenny, D. (ed.). Human issues in translation technology. Oxon/New York: Routledge, pp. 46-62.

Marshman, E. (2014). Taking Control: Language Professionals and Their Perception of Control when Using Language Technologies. Meta, Translators' Journal, v. 59, n. 2, p. 380-405. 〈https://doi.org/10.7202/1027481ar〉. [Accessed: 20211115].

Mikhailov, M. (2015). Minor language, major challenges: the results of a survey into the IT competences of Finnish translators. JosTrans, Journal of Specialised Translation, n. 24, pp. 89-111. 〈https://jostrans.org/issue24/art_mikhailov.php〉. [Accessed: 20210202].

Moore, G. C.; Benbasat, I. (1991). Development of an Instrument to Measure the Perceptions of Adopting an Information Technology Innovation. Information Systems Research, v. 2. n. 3, pp. 192-222.

Moorkens, J. (2020). Comparative satisfaction among freelance and directly-employed Irish-language translators. Translation \& Interpreting, v. 12, n. 1, pp. 55-73. 〈https://doi.org/10.12807/ti.112201.2020.a04〉. [Accessed: 20211116]. 
Olohan, M. (2019). Sociological approaches to translation technology. In: O'Hagan, M. (ed.). The Routledge Handbook of Translation and Technology, Milton: Routledge, pp. 384-397.

Pielmeier, H.; O'Mara, P. (2020). The State of the Linguist Supply Chain: Translators and Interpreters in 2020. CSA Research. 〈https://insights.csaresearch.com/reportaction/305013106/Toc〉. [Accessed: 20210202].

Rothwell, A.; Svoboda, T. (2018). Tracking translator training in tools and technologies: findings of the EMT survey 2017. Jostrans, Journal of Specialised Translation, n. 32, pp. 26-60. 〈https://jostrans.org/issue32/art_rothwell.php〉. [Accessed: 20210202].

Ruokonen, M. (2018). To Protect or Not to Protect: Finnish Translators' Perceptions on Translator Status and Authorisation. Hermes, Journal of Language and Communication in Business, n. 58, pp. 65-82. 〈https://tidsskrift.dk/her/issue/view/7564〉. [Accessed: 20210202].

Ruokonen, M.; Mäkisalo, J. (2018). Middling-Status Profession, High-Status Work: Finnish Translators' Status Perceptions in the light of their Backgrounds, Working Conditions and Job Satisfaction. Translation \& Interpreting, v. 10, n. 1, pp. 1-17. 〈https://doi.org/10.12807/ti.110201.2018.a01〉. [Accessed: 20211116].

Salmi, H. (2012). Evidence of bridging the gap between formal education and informal learning through teacher education. Reflecting Education, v. 8, n. 2, pp. 45-61. 〈http://www.reflectingeducation.net/index.php/reflecting/issue/view/12/showToc〉. [Accessed: 20210620].

Salmi, H.; Kaasinen, A.; Kallunki, V. (2012). Towards an Open Learning Environment via Augmented Reality (AR): visualising the invisible in science centres and schools for teachers. Procedia, Social and Behavioral Sciences, v. 45, pp. 284-295. 〈https://doi.org/10.1016/j.sbspro.2012.06.565〉. [Accessed: 20211115].

Salmi, L. (2014). Kääntäjäopiskelijoiden suhtautuminen käännösteknologiaan [Translator students' perception of translation technology], MikaEL, Electronic Proceedings of the KäTu Symposium on Translation and Interpreting Studies, v. 8, pp. 55-73. 〈https://www.sktl.fi/liitto/seminaarit/mikael-verkkojulkaisu/arkisto-archive/vol-82014/>. [Accessed: 20210620].

Suppanen, O. (2015). "Freelancerin nyt pitää sitten osata itse oikeastaan kaikki": Kääntäjien tietoteknisten taitojen kartoitusta kyselytutkimuksella ["Well. freelancers have to know how to do just about everything themselves". Surveying the ICT skills of translators.] Master's Thesis. University of Tampere. 〈http://urn.fi/URN:NBN:fi:uta201510292387>. [Accessed: 20210202].

Vieira, L. N. (2020). Automation anxiety and translators. Translation Studies, v. 13, n. 1, pp. 1-21. 〈https://doi.org/10.1080/14781700.2018.1543613〉. [Accessed: 20211116].

Virtanen, T. (2019). What makes a government translator tick? Examining the Finnish government English translators' perceptions of translator status, job satisfaction and the underlying factors. Doctoral Thesis. Department of Modern Languages, Faculty of 
Arts, University of Helsinki. 〈http://urn.fi/URN:ISBN:978-951-51-5535-1〉. [Accessed: 20210202]. 